If the end of the implanted artery forms a communication with capillaries of granulation tissue from the myocardium these will dilate and later take on the morphological and functional characteristics of arterioles joining the two arteries.

The capacity to form larger collaterals may be limited in diseased or older vessels and they form too slowly to prevent tissue necrosis if larger arterioles are occluded. However, there is evidence that collaterals form in the same way in the human retina (Dollery et al., 1967).

Further work will be needed to establish the relative importance of various factors that may facilitate or retard the formation of collaterals.

\section{References}

Ashton, N., Dollery, C.T., Henkind, P., Hill, D.W., Paterson, J.W., Ramalho, P.S. \& Shakib, M. (1966) Focal retinal ischaemia: ophthalmoscopic, circulatory and ultrastructural changes. Brit. J. Ophthal. 50, 281.

AsHTon, N. \& HeNkIND, P. (1965) Experimental occlusion of retinal arterioles. Brit. J. Ophthal. 49, 225.

Dollery, C.T., Hill, D.W., Paterson, J.W., Ramalho, P.S. \& KoHNER, E.M. (1967) Collateral blood flow after branch arteriolar occlusion in the human retina. Brit. J. Ophthal. 51, 249.

Permutt, S. \& Riley, R.L. (1963) Haemodynamics of collapsible vessels with tone: the vascular waterfall. J. appl. Physiol. 18, 924.

Wiedeman, M.P. (1963) Patterns of the arterio-venous pathways. Handbook of Physiology. Circulation, 2, 891. American Physiology Society, Washington, D.C.

WISSLER, R.W. (1967) The arterial medial cell, smooth muscle or multifunctional mesenchyme. Circulation, 36, 1 .

\title{
Studies on the metabolism of angiotensin
}

\author{
Austin E. Doyle \\ Department of Medicine, University of Melbourne*
}

THE pressor octapeptide angiotensin is formed by the action of the enzyme renin on a plasma substrate. The amino-acid sequence of angiotensin II was determined by Skeggs et al. (1956), and synthesis of biologically active peptides was subsequently achieved by Bumpus, Schwarz \& Page (1957) and by Schwyzer et al. (1958). The level of angiotensin found in arterial blood in healthy individuals is usually less than $20 \mathrm{ng} / 100$ $\mathrm{ml}$ (Kahn et al., 1952; Massani et al., 1966). Raised levels of angiotensin have been found in the arterial blood of patients with oedema or sodium depletion and in some patients with hypertension (Kahn et al., 1952 ; Boucher et al., 1964 ; Massani et al., 1966).

The significance of raised plasma levels can only be assessed if knowledge is available as to the speed with which angiotensin liberated into the circulation is removed from it. Such evidence as is available suggests that angiotensin is rapidly removed from the circulation, but there is little knowledge of the mechanism involved. Moreover, little is known of the relationship between the biological effects and plasma levels, or of the relationship between the destruction of angiotensin by plasma enzymes and the limitation of biological activity.

Methods in this field are difficult to apply to these problems. Hitherto, all assays of angio-

\footnotetext{
* Postal address: Department of Medicine, Austin Hospital, Heidelberg N.22, Victoria, Australia.
}

tensin in biological fluids have depended on biological assay. Previous attempts to devise labelling techniques with ${ }^{131} \mathrm{I}$ have led to almost complete loss of biological activity (Cruz-Coke, 1946; Barbour \& Bartter, 1963), while randomly tritiated material is unstable (Barbour \& Bartter, 1963) and has the disadvantage that radioactive fragments of various types may make isolation and identification of metabolic products difficult.

Some of these difficulties have been overcome by the use of ${ }^{35}$ S]phenylisothiocyanate to form [ ${ }^{35}$ S]phenylthiocarbamyl (PTC) angiotensin (Osborn, Louis \& Doyle, 1966). By this technique angiotensin II can be specifically labelled with $\left[{ }^{35}\right.$ S]phenylisothiocyanate, and the derivative so formed can be readily separated from angiotensin II and retains biological activity. PTC angiotensin exhibits about $25-30 \%$ of the pressor effect of the unlabelled octapeptide, and has a parallel dose-response curve (Fig. 1). Moreover, during tachyphylaxis to unlabelled angiotensin, pressor responses to PTC angiotensin also disappear (Fig. 2). These observations suggested that the biological site of action and the metabolism of the labelled derivative might be similar to that of the original octapeptide, and that $\left[{ }^{35}\right.$ S]PTC angiotensin might be of value in elucidating the site of action and metabolic fate of angiotensin.

The suggestion has been made that variations in plasma angiotensinase activity might be of 


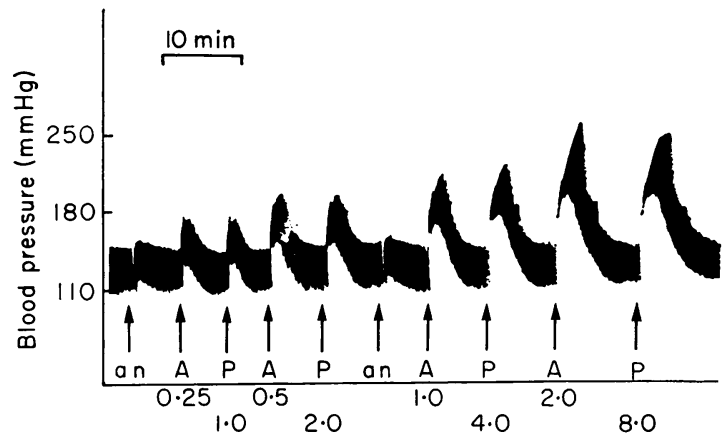

FIG. 1. The rises in blood pressure induced in the anaesthetized dog by various doses of angiotensin (A) and $\left.{ }^{[3} \mathrm{S}\right] \mathrm{PTC}$ angiotensin (P). The dose-response curves are parallel, but the unlabelled angiotensin is about four times as potent as the labelled material. All doses shown are in $\mu \mathrm{g}$. 'an' refers to anaesthetic.

importance in determining whether the pressor effect of angiotensin varies in different pathological states. Thus Wood (1962) found that relatives of hypertensive patients had less angiotensinase activity than those of normal people, whereas Hickler, Lauler \& Thorn (1963) stated that plasma angiotensinase activity was augmented in hypertensive individuals, which they thought to be evidence for a long-standing increase in angiotensin production. Not much is known about the importance of plasma enzymes in limiting biological activity. There is evidence that $\beta$-aspartyl-angiotensin II is more stable in plasma than the naturally occurring $\alpha$-aspartyl peptide (Bumpus et al., 1964) and the biological activity of $\beta$-aspartyl-angiotensin has been claimed to be more prolonged (Imhoff et al., 1964).

The availability of a radioactive analogue of angiotensin has allowed a new approach to this problem to be made (Doyle, Louis \& Osborn,

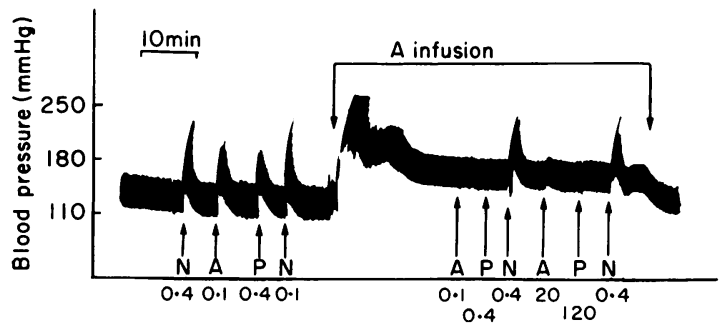

FIG. 2. The effects on blood pressure in the anaesthetized dog of injections of noradrenaline $(N)$, angiotensin (A) and $\left[{ }^{35}\right.$ S $]$ PTC angiotensin (P) before and during the infusion of a large dose of unlabelled angiotensin. All doses shown are in $\mu \mathrm{g}$. The large doses of angiotensin and ${ }^{35}$ S $]$ PTC angiotensin given during the infusion induced no pressor response, indicating that tachyphylaxis to both substances had been induced by the infusion of angiotensin. The pressor response to noradrenaline persisted.
1967). When ${ }^{35}$ S $]$ PTC angiotensin is incubated with plasma at $37^{\circ}$ and subsequently submitted to paper chromatography, the amount of $\left[{ }^{35}\right.$ S]PTC angiotensin diminishes progressively with incubation and two new peaks appear, which probably represent metabolic products (Fig. 3). The rate of destruction of PTC angio-

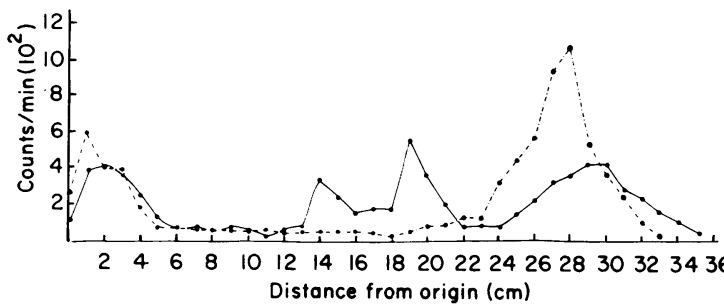

FIG. 3. The distribution of radioactivity along the paper chromatogram following incubation of $\left[{ }^{35}\right.$ S]PTC angiotensin with plasma at $37^{\circ}$. The interrupted lines represent the radioactivity of the sample stopped at zero time with a peak of $R_{F} \mathbf{0} 80$. The continuous lines represent the radioactivity of the sample incubated for $6 \mathrm{hr}$ at $37^{\circ}$. The peak previously present is smaller and two new peaks have developed, probably representing metabolic products of $\left[{ }^{35} \mathrm{~S}\right] \mathrm{PTC}$ angiotensin. The peak at the origin is probably contaminating radioactivity.

tensin by plasma is slowed by the presence of excess unlabelled angiotensin, the addition of $\vec{\bullet}$ the disodium salt of ethylenediamine tetra-acetie $\infty$ acid (EDTA), or by lowering the incubating temperature (Fig. 4). The rate of destruction of

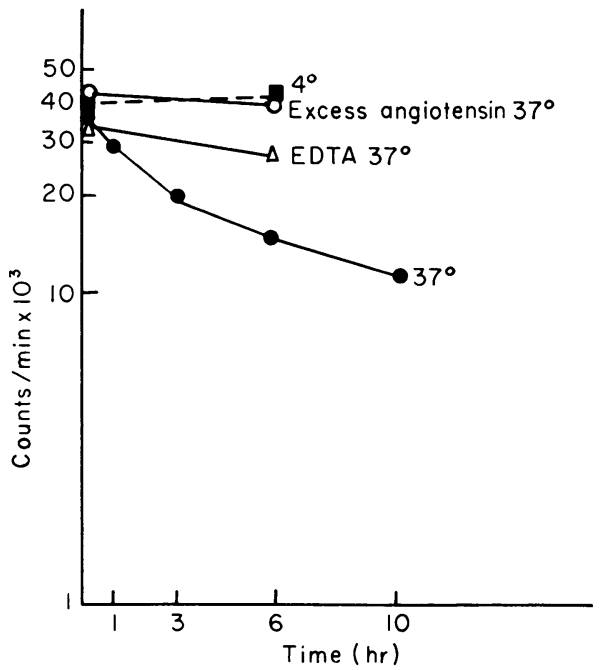

FIG. 4. The relationship between the radioactivity present at $R_{F} \mathbf{0 . 8 0}$ after chromatography of plasma incubated for various times with [ $\left.{ }^{35} \mathrm{~S}\right] \mathrm{PTC}$ angiotensin. Each line represents the mean of three experiments in which plasma and $\left[{ }^{55}\right.$ S]PTC angiotensin were incubated at $37^{\circ}$, either alone or with $500 \mu \mathrm{g}$ of $\alpha$-aspartyl-angiotensin, or with EDTA. In one group of experiments plasma and ${ }^{36}$ S]PTC angiotensin were incubated at $4^{\circ}$. 
PTC angiotensin was comparatively slow. Studies on the rate at which the biological effects of angiotensin II, PTC angiotensin, angiotensin labelled with fluorescein isothiocyanate, or $\beta$ aspartyl-angiotensin were lost on incubation with plasma, showed that the $\alpha$-aspartyl-angiotensin was inactivated by plasma much more rapidly than the three analogues (Figs. 5, 6 and 7). The pro-

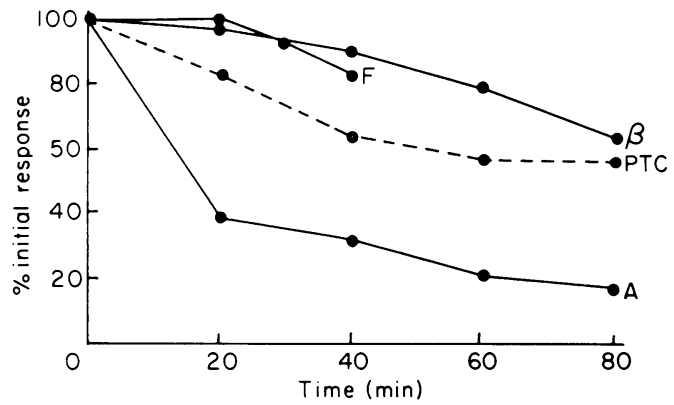

FIG. 5. The relationship between time and the percentage of the initial biological activity remaining after the incubation of various analogues of angiotensin with plasma. The ordinate is the rise in blood pressure at various times expressed as a percentage of the rise in blood pressure produced by each compound at zero time. $A$ is $\alpha$-aspartyl-angiotensin II, $B$ is $\beta$-aspartyl-angiotensin II, PTC is $\left[{ }^{35}\right.$ S $]$ PTC angiotensin, and F is angiotensin labelled with fluorescein isothiocyanate. Each line represents the mean of three experiments, except for $A$ which represents the mean of nine experiments.

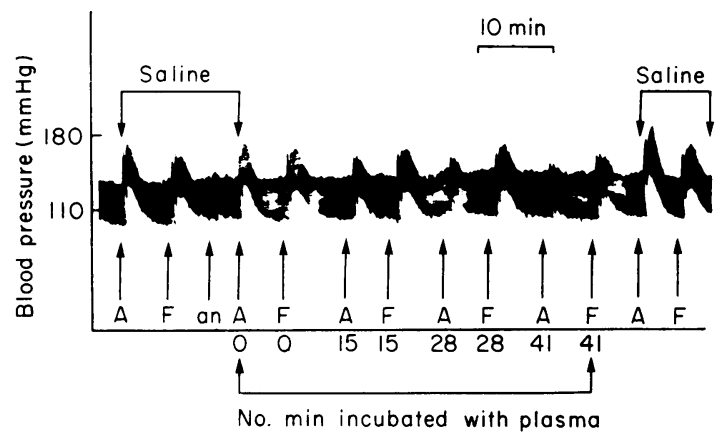

FIG. 6. The pressor responses induced by $\alpha$-aspartylangiotensin II (A) and fluorescein-labelled angiotensin (F) in an anaesthetized dog. The first two injections and the last two injections were made up in saline and were given to ensure that the responsiveness of the preparation had not altered during the experiment. The remaining injections were aliquots of $\alpha$-aspartyl-angiotension (A) or fluorescein-labelled angiotensin (F) which had been incubated with plasma for varying periods of time. The length of time for the period of incubation is shown by the figures under the blood pressure tracing. Whereas the response to $\alpha$-aspartyl-angiotensin diminished progressively with incubation, that induced by fluorescein labelled angiotensin was little affected (see Fig. 5). tection afforded by the $\beta$ configuration or by the attachment of phenylisothiocyanate or fluorescein isothiocyanate to the terminal $-\mathrm{NH}_{2}$ group, indicates that plasma angiotensinase activity is mainly due to an aminopeptidase as suggested by Bumpus et al. (1964) and by Nagatsu et al. (1965). The results obtained using $\left[{ }^{35} \mathrm{~S}\right] \mathrm{PTC}$ angiotensin suggest that other enzyme systems operate in plasma, although very slowly, with the formation of labelled peptide fragments. The major fragment has chromatographic characteristics which closely resemble those of the PTC tetrapeptide, phenylthiocarbamyl asparaginyl-arginyl-valyl-tyrosine, formed by the action of chymotrypsin on angiotensin (Osborn, Doyle \& Murray, 1967). The fact that excess unlabelled angiotensin retards this reaction suggests that this enzyme probably also attacks angiotensin.
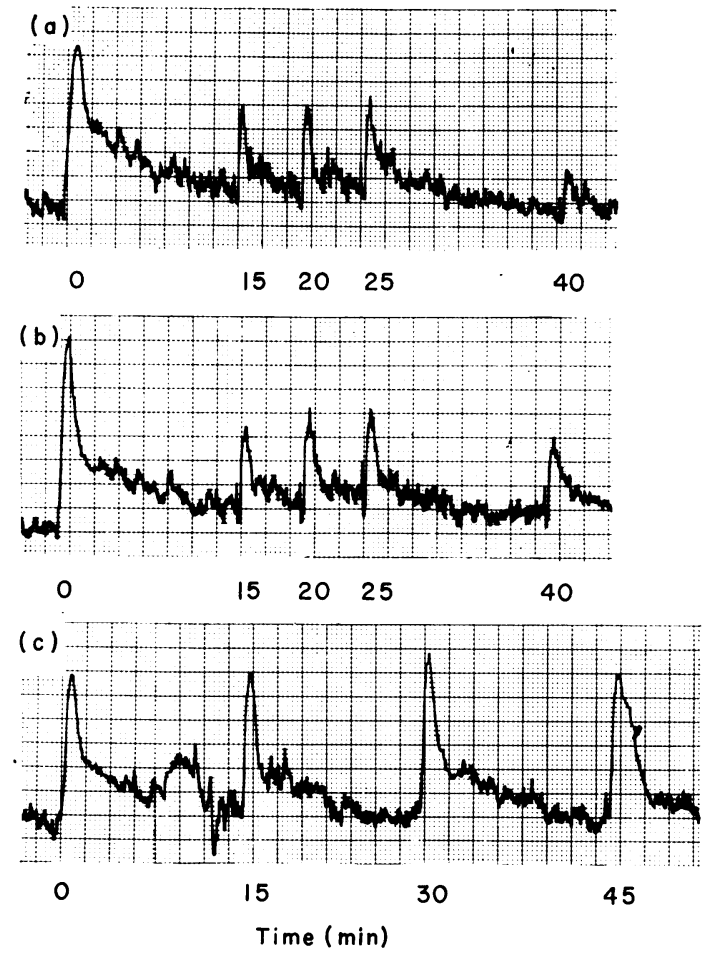

FIG. 7. The response of the superfused rat colon to: (a) $\alpha$-aspartyl-angiotensin incubated with whole fresh human blood, (b) $\alpha$-aspartyl-angiotensin incubated with fresh human plasma, and (c) to PTC angiotensin incubated with fresh human plasma. Both blood and plasma sharply reduced the effects of $\alpha$-aspartyl-angiotensin, but plasma had little effect on the action of PTC angiotensin. 
It is of interest that in spite of the differences in plasma angiotensinase activity on $\alpha$-aspartylangiotensin and its analogues, the biological effects of all seem equally brief, and all exhibit parallel dose-response curves. This suggests that plasma angiotensinase activity is not an important factor in limiting biological activity. Further evidence that enzyme activity is not disturbed in pathological states is provided by the studies of Osborn \& Jerums (1967, personal communication), who found no sighificant differences in inactivation rates of angiotensin or destruction rates of $\left[{ }^{35} \mathrm{~S}\right] \mathrm{PTC}$ angiotensin in plasmas from normal individuals and plasmas from patients with hypertension or renal failure.

The information which can be derived from in vitro studies is limited. The use of a labelled derivative has enabled us also to study the relationship existing between blood levels, pressor effects, infusion rates and the formation of metabolic products. In these experiments anaesthetized mongrel dogs were infused intravenously with various doses of $\left[{ }^{35} \mathrm{~S}\right] \mathrm{PTC}$ angiotensin or angiotensin II, the changes in mean blood pressure recorded and arterial and venous blood samples taken before, during and after the infusions. The blood samples were taken into methanol, centrifuged and the methanolic supernatant dried, extracted with ether and redissolved in methanol for paper chromatography. In each experiment recovery studies in which $200 \mathrm{ng}$ of $\left[{ }^{35}\right.$ S $]$ PTC angiotensin was added to blood were performed. In the experiments in which unlabelled angiotensin was used bioassay was performed using the superfused rat colon (Regoli \& Vane, 1964).

In both arterial and venous samples taken during the infusion of $\left[{ }^{35}\right.$ S $]$ PTC angiotensin a radioactive peak with an $\mathbf{R}_{\mathbf{F}}$ corresponding to that of PTC angiotensin was present. The magnitude of this peak did not increase with continued infusion, but reached a constant level, the height of which was related to the infusion rate. Infusions of $0.5 \mu \mathrm{g} / \mathrm{min}$ led to a mean arterial blood level of PTC angiotensin of $30 \mu \mathrm{g} / 100 \mathrm{ml}$, infusions of $1.0 \mu \mathrm{g} / \mathrm{min}$ gave a level of $64 \mu \mathrm{g} /$ $100 \mathrm{ml}$ and in fusions of $5.0 \mu \mathrm{g} / \mathrm{min}$ gave a level of $360 \mu \mathrm{g} / 100 \mathrm{ml}$. At all infusion rates, the concentrations in venous blood were about half those found in arterial blood.

Both arterial and venous blood samples taken during the infusion contained a second radioactive substance, whose $R_{F}$ resembled that of the metabolic product seen on in vitro incubation with plasma. This peak was usually bigger than the one corresponding to PTC angiotensin and its magnitude increased both with the size of the dose infused and with the duration of the infusion. This material was thought to be a metabolic product of the radioactive hormone.

After the infusion was discontinued the arterial blood level of PTC angiotensin fell very rapidly ; the 'half-time' was always under 2 min and all the PTC angiotensin had disappeared within 3-5 min of the infusion being stopped. However, the level of the radioactive metabolite fell much less rapidly, and was still detectable in the arterial blood $25 \mathrm{~min}$ after stopping the infusion. The blood pressure fell rapidly on stopping the infusion but remained above resting levels for almost $10 \mathrm{~min}$.

Infusion of $5 \mu \mathrm{g} / \mathrm{min}$ of non-radioactive angiotensin gave an arterial blood level of $160 \mathrm{ng} / 100$ $\mathrm{ml}$. Lower infusion rates gave blood levels not detectable by this method on samples of $10 \mathrm{ml}$. At no dose level was angiotensin detected in venous blood.

It is evident that both angiotensin and $\left.{ }^{35} \mathrm{~S}\right] \mathrm{PTC}$ angiotensin are removed very rapidly from the circulation, and that the clearance is substantially complete in a single circulation. If the results found here apply also to man, production rates of angiotensin might have to reach $5-10 \mu \mathrm{g} /$ min to allow arterial blood levels to approach those found in secondary aldosteronism or malignant hypertension. It is evident that a study of blood levels may not be the best way of determining the production rate of angiotensin and it is possible that measurement of a specific metabolic product may be of more value in estimating this.

\section{Acknowledgments}

Figs. 1 and 2 appeared in Aust. J. exp. Biol. med. Sci. (1966) 44, 475, Figs. 3-7 appeared in Aust. J. exp. Biol. med. Sci. (1967) 45, 41; and are reproduced by kind permission of the Editor.

\section{References}

Barbour, B.H. \& BarTter, F.C. (1963) Angiotensin labelled with ${ }^{131} I$ and with tritium. J. clin. Endocr. 23, 313.

Boucher, R., Veyrat, R., Champlain, J. De \& Genest, J. (1964) New procedures for measurement of human plasma angiotensin and renin activity levels. Can. med. Ass. J. 90, 194.

Bumpus, F.M., Schwarz, H. \& Page, I.H. (1957) Synthesis and pharmacology of the octapeptide angiotonin. Science, 125, 886.

Bumpus, F.M., Smeby, R.R., Page, I.H. \& Khairallah, P.A. (1964) Distribution and metabolic fate of angiotensin II and various derivatives. Can. med. Ass. J. 90, 190.

Cruz-CoKe, E. (1946) Experimental Hypertension (Ed. by R. W. Miner), Vol. III, p. 32. New York Academy of Sciences.

Doyle, A.E., Louis, W.J. \& Osborn, E.C. (1967) Plasma angiotensinase activity on angiotensin II and analogues. Aust. J. exp. Biol. med. Sci. 45, 41.

Hickler, R.B., LaUler, D.P. \& ThorN, G.W. (1963) Plasma angiotensinase activity in patients with hypertension and oedema. J. clin. Invest. 42, 635. 
Imhof, P., Brunner, H., Quitt, J., SteinmanN, B. \& JACONO, A. (1964) Experimentelle und Klinische Untersuchungen mit $\beta$-angiotensin-II (Präparat Ciba 33 902-Ba), einem neuen Angiotensin-II-Analogen mit verstärkter und verlängerter pressorischer Wirkung. Schweiz. med. Wschr. 94, 1199.

Kahn, J.R., Skeggs, L.T., Shumway, N.P. \& Wisenbaugh, P.E. (1952) The assay of hypertensin from the arterial blood of normotensive and hypertensive human beings. J. exp. Med. 95, 523.

Massani, Z.M., Finkielman, S., Worcel, M., Agrest, A. \& Paladini, A.C. (1966) Angiotensin blood levels in hypertensive and non-hypertensive diseases. Clin. Sci. 30, 473.

Nagatsu, I., Gillespie, L., Folk, J.E. \& Glenner, G.G. (1965) Serum aminopeptidases and hypertensin-I. Degradation of angiotensin II by human serum. Biochem. Pharmacol. 14, 721.

OsboRn, E.C., LouIs, W.J. \& Doyle, A.E. (1966) Preparation, isolation and properties of [ ${ }^{35}$ S]phenylthiocarbamyl angiotensin. Aust. J. exp. Biol. med. Sci. 44, 475.
Osborn, E.C., Doyle, A.E. \& Murray, M. (1967) The action of trypsin and of chymotrypsin on phenylthiocarbamyl-angiotensin II. Aust. J. exp. Biol. med. Sci. 45, 261.

Regol, D. \& VANe, J.R. (1964) A sensitive method for the assay of angiotensin. Brit. J. Pharmacol. 23, 351.

SCHWyzer, R., Iselin, B., KAPPeler, H., Riniker, B., Rittel, W. \& Zuber, H. (1958) Synthese hochwirksamer Oktapeptide mit der Vermutlichen Aminosauresequenz des noch unbekannten Hypertensins II aus Rinderserum (Val ${ }^{5}$-Hypertensin II und $\mathrm{Val}^{5}$-Hypertensin II-Asp-B-amid). Helv. chim. Acta, 41, 1287.

Skeggs, L.T., Lentz, K.E., KAHN, J.R., Shumway, N.P. \& Woods, K.R. (1956) The amino acid sequence of hypertensin II. J. exp. Med. 104, 193.

Wood, J.E. (1962) Genetic control of neutralization of angiotensin and its relationship to essential hypertension. Circulation, 25, 225.

\title{
Forearm blood flow and heart rate after haemorrhage
}

\author{
O. G. EDHOLM \\ J. D. HATCHER* \\ Division of Human Physiology, National Institute for Medical Research
}

THE EFFECTS of venesection on the cardiovascular system in man were studied by Barcroft et al. (1944). When fainting occurred there was a sudden fall of blood pressure, bradycardia, pallor, sweating and a marked though transient muscle vasodilatation. In these and subsequent studies, observations were not prolonged after recovery from fainting. There have been only a few studies of the effects of venesection, uncomplicated by fainting, on the peripheral circulation in man. De Wardener et al. (1953) followed the changes in forearm blood flow in nine subjects under light anaesthesia when they were bled an average of $1175 \mathrm{ml}$. There was a fall in forearm blood flow from the beginning to the end of venesection, the initial level being $6.6 \mathrm{ml} / 100 \mathrm{ml}$ fore$\mathrm{arm} / \mathrm{min}$ to $2.1 \mathrm{ml}$, and this level persisted until retransfusion some $20-80 \mathrm{~min}$ later. It was suggested that anaesthesia prevented the reactions observed in vasovagal fainting.

It is of some importance to know what the changes might be in venesection without anaesthesia, and also to follow the effects of venesection for several hours. The observations reported in this paper are confined to changes in forearm blood flow, blood pressure and heart rate, in

\footnotetext{
* Present address: Department of Physiology, Queen's University, Kingston, Ontario, Canada.
}

subjects who had substantial quantities of blood removed, only some of whom fainted.

\section{Subjects}

The majority of the subjects were medically qualified, the others were senior medical students (Table 1).

TABle 1

Characteristics of subjects

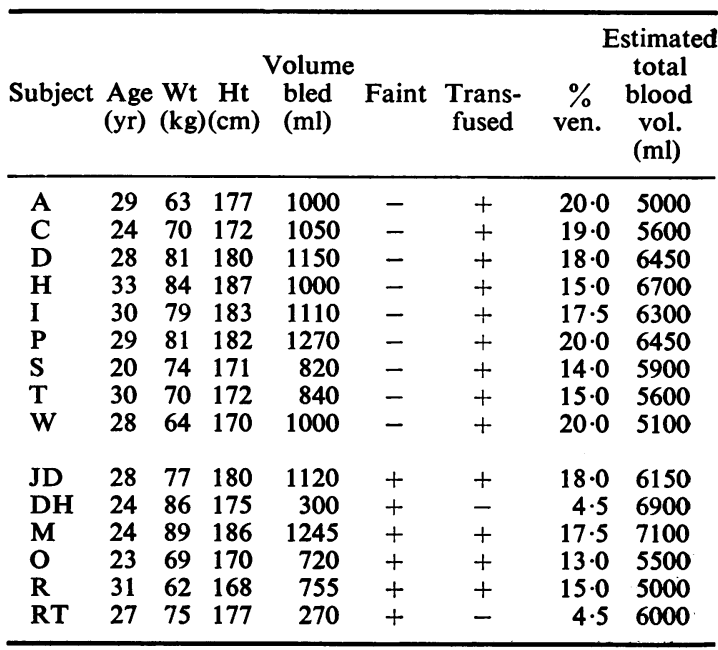

